\title{
PRODUTIVIDADE E QUALIDADE DE SEMENTES DE ARROZ PRODUZIDAS SOB INUNDAÇÃO EM DIFERENTES CLASSES DE SOLOS DE VÁRZEA
}

\author{
ANTÔNIO RODRIGUES VIEIRA ${ }^{1}$ \\ JOÃO ALMIR OLIVEIRA ${ }^{2}$ \\ TATIANA GROSSI CHQUILOFF VIEIRA ${ }^{3}$
}

\begin{abstract}
RESUMO - Os solos de várzea, por possuírem origem diversa, são muito heterogêneos em relação à sua composição granulométrica e mineralógica, resultando em comportamento diferente dos demais solos quando submetidos a processos produtivos. Sua influência na produtividade e qualidade fisiológica de sementes foi investigada utilizando sementes de arroz irrigado, cultivares Capivari, Sapucaí, Urucuia, Inca e MG 1, produzidas em 94/95 e 95/96, em três tipos de solos: Organossolo Fólico, Gleissolo Melânico e Gleissolo Háplico, encontrados no Campo Experimental da EPAMIG, localizado no município de Cambuquira. As
\end{abstract}

sementes colhidas foram avaliadas utilizando os parâmetros: produção, germinação-padrão e vigor, por meio de testes de $1^{\mathrm{a}}$ contagem de germinação e comprimento de raiz. Pelos resultados, pode-se observar que as maiores produções de sementes foram obtidas no Gleissolo Háplico, e as menores, quando produzidas no Organossolo Fólico. Também foi verificado que em qualquer tipo de solo estudado as cultivares Urucuia e MG 1 foram as mais produtivas. Foi observado ainda que, independente da cultivar avaliada, as sementes produzidas no Gleissolo Háplico apresentaram melhor qualidade fisiológica.

TERMOS PARA INDEXAÇÃO: Sementes, arroz, cultivares, solos de várzea, Oryza sativa.

\section{YIELD AND QUALITY OF RICE SEEDS PRODUCED UNDER FLOODING CONDITIONS IN DIFERENT WETLAND SOILS}

\begin{abstract}
Wetlands, due to their heterogeneous origins, vary significantly in their granulometric and mineralogic composition, which results in different behaviors when under agriculture. The influence of the wetlands in the productivity and seed physiological quality was tested using seeds of irrigated rice, from cultivars Capivari, Sapucaí, Urucuia, Inca e MG 1, produced in 94/95 and 95/96, on three different soils: Folic Organosol, Melanic Gleisol, and Haplic Gleisol. All soils are from the Experimental EPAMIG Farm, Cambuquira (MG). The harvested
\end{abstract}

seeds were evaluated using the following parameters: field production, germination (standard test), and vigor, through germination counting and root length. The results showed that the largest production of seeds came from the Haplic Gleisol and the smallest from the Folic Organosol. It was also verified that in all studied soils, the cultivars Urucuia and MG 1 were the most productive. Additionally, it was observed that, in all cultivars, the best seed physiological quality was obtained in the Haplic Gleisol.

INDEX TERMS: Seeds, rice, cultivars, wetlands, Oryza sativa.

\section{INTRODUÇÃO}

O arroz (Oryza sativa L.) constitui-se em alimento básico da maior parte da população brasileira, havendo, atualmente, necessidade de se aumentar a produção de grãos para atender à crescente demanda decorrente do aumento populacional (Fornasieri Filho \& Fornasieri, 1993).

1. Engenheiro Agrônomo, Dr., Pesquisador, EPAMIG/CTSM, Caixa Postal 176, 37200-000 - Lavras, MG.

2. Biólogo, Dr., Pesquisador, UNIVERSIDADE FEDERAL DE LAVRAS/UFLA, Caixa Postal 37, 37200-000 - Lavras, MG.

3. Engenheiro Agrimensor, M.Sc., Pesquisadora, EPAMIG/CTSM. 
Em virtude de o arroz ser uma espécie cultivada que se desenvolve em áreas úmidas e do vasto potencial de várzeas existentes em Minas Gerais (1,5 milhão de hectares), torna-se evidente que a expansão da produção dessa gramínea está na dependência da incorporação dessas áreas no processo produtivo. Entretanto, para inserir as várzeas nesse processo, não basta somente a execução de obras de irrigação e drenagem, de sistematização de solos, de proteção e controle de enchentes, de saneamento agrícola e ratificação de cursos d'água. Também não se pode concebê-las como possuidoras de um mesmo tipo de solo e usar um mesmo método, indiscriminadamente, para todos projetos, quer seja para a pesquisa, quer seja para produção de grãos ou sementes (Ruralminas, 1980; Novaes, 1988).

Por serem originados de sedimentos com grande heterogeneidade quanto à composição granulométrica e mineralógica, os solos de várzea apresentam uma diversidade muito grande de características físicas e químicas, resultando em comportamentos diferentes, quando submetidos a processos produtivos, ainda que sob o mesmo sistema de manejo. A decorrência imediata disso é que classes de solos diferentes necessitam de tratamentos diferentes. Esse aspecto, da mais alta importância, nem sempre é levado em consideração nos trabalhos de pesquisa, o que dificulta ou mesmo impossibilita a extrapolação dos resultados da pesquisa para outros locais de solos semelhantes (Resende, 1982; Curi et al., 1988).

Conforme é sabido, esses solos, em estado natural, não apresentam problemas quanto à deficiência de água e são de baixa susceptibilidade à erosão; porém, apresentam deficiência de fertilidade. No entanto, uma característica dominante nesses solos é a má drenagem ou hidromorfismo, embora aqueles situados em terraços ou níveis mais elevados possam apresentar-se menos maldrenados (Curi et al., 1988). Esses solos, quando cultivados sob inundação, apresentam características bastante adversas daquelas verificadas em condições de boa drenagem, o que pode acarretar mudanças no comportamento dos nutrientes, tanto daqueles nativos como dos adicionados no solo, afetando o desenvolvimento das plantas e, conseqüentemente, a produtividade e a qualidade das sementes produzidas, Guilherme (1990).

A vitalidade da semente de arroz depende em parte do vigor de seus ascendentes, razão pela qual se recomenda que os campos de produção sejam instalados em terrenos mais férteis. Áreas onde ocorrem desuniformidade na fertilidade propiciam crescimento e maturação desuniformes, podendo, com isso, prejudicar a formação e o desenvolvimento das sementes. Nesse contexto, uma planta bem-nutrida apresenta-se em condições de produzir sementes bem formadas (Faria \& Azevedo, 1984). Entretanto, as respostas à aplicação de nutrientes podem variar também em função da cultivar utilizada, pois, algumas podem extrair os elementos essenciais mais eficientemente do que outras, mesmo em solos deficientes. Essas diferenças encontradas podem ser explicadas por seus mecanismos fisiológicos com diferentes taxas de absorção e translocação e diferenças morfológicas nos seus sistemas radiculares (Malavolta \& Fornasiere Filho, 1983; Lopes, 1996). Porém, de qualquer forma, além da capacidade adaptativa, o aumento na disponibilidade de nutrientes nos solos inundados contribui para um melhor estado nutricional e maior produtividade do arroz em sistema de inundação. Vale ressaltar, ainda, que de um modo geral, a alta produtividade obtida com o arroz irrigado é o resultado da interação das características ambientais e genéticas da cultivar utilizada.

Em face dessas considerações, com a presente pesquisa objetivou-se avaliar a produção e a qualidade fisiológica de sementes de arroz cultivadas sob sistema de inundação, em diferentes classes de solos de várzea.

\section{MATERIAL E MÉTODOS}

O estudo foi realizado em um Campo Experimental da EPAMIG, localizado em Cambuquira (MG).

Anteriormente à instalação do experimento, a área foi percorrida e os solos previamente classificados segundo metodologia preconizada pelo Sistema Brasileiro de Classificação de Solos (EMBRAPA, 1999). Foram encontrados três solos: Organossolo Fólico, Gleissolo Melânico e Gleissolo Háplico. As análises desses solos nos dois anos de cultivo foram realizadas utilizando a metodologia proposta por Vettori (1969) e modificada pela EMBRAPA (1979) e Camargo et al. (1986), e os resultados estão apresentados na Tabela 1. Com base nesses resultados, realizou-se a correção do solo (calagem) e adubação, conforme a recomendação da CFSEMG (1989) para a cultura do arroz.

Para implantação do experimento no campo, adotou-se o delineamento de blocos ao acaso, com quatro repetições, e cada bloco apresentava uma área de 240 $\mathrm{m}^{2}$. Foi utilizado o esquema fatorial $(3 \times 5)$, sendo 3 solos (Organossolo Fólico, Gleissolo Melânico e Gleissolo Háplico) e 5 cultivares irrigadas (Capivari, Sapucaí, Urucuia, Inca e MG 1). 
As sementes utilizadas no experimento, provenientes do estoque genético da EPAMIG, foram tratadas com Furadan 350, na dosagem de 1,5 L/100 kg de sementes, para o controle preventivo de pragas e semeadas em canteiros. Após 30 dias, foi feito o transplantio, colocando-se 4 mudas por cova, espaçadas de $0,20 \mathrm{~m}$ dentro da linha. As parcelas constituíram-se de 6 linhas de $5 \mathrm{~m}$ de comprimento, espaçadas de $0,30 \mathrm{~m}$ entre si, sendo a área útil constituída das 4 fileiras internas. As plantas daninhas foram controladas por capinas manuais e pela lâmina d'água, mantendo-se os ensaios livres de invasoras. A água foi somente retirada próximo à maturação das sementes. A colheita foi processada quando as sementes atingiram a umidade de 20 a $22 \%$.

A produção de sementes foi obtida pela pesagem de todas as sementes da parcela útil, após a limpeza e secagem uniforme ao sol, até atingirem a umidade homogênea, em torno de $13 \%$.
A avaliação da qualidade fisiológica das sementes foi feita após a determinação da produção, sendo realizados testes de germinação e testes de vigor. Para tanto, a dormência das sementes (característica apresentada por cultivares irrigadas de arroz após a colheita) foi superada com o tratamento em estufa de circulação forçada de ar a $40^{\circ} \mathrm{C}$ por 7 dias (Vieira et al., 1994) e, em seguida, as sementes foram submetidas ao teste-padrão de germinação, seguindo os critérios estabelecidos pelas Regras para Análise de Sementes (Brasil, 1992). O teste de vigor foi realizado no $7^{\circ}$ dia, durante o teste de germinação, sendo determinados os parâmetros $1^{\text {a }}$ contagem de germinação (plantas normais) e comprimento médio de raiz.

As variáveis estudadas tiveram seus dados submetidos à análise de variância e as médias, comparadas pelo teste de Tukey a $5 \%$ de probabilidade.

TABELA 1 - Resultados das análises de fertilidade, matéria orgânica e textura de três solos de várzea de Cambuquira (MG), em dois anos.

\begin{tabular}{|c|c|c|c|c|c|c|}
\hline \multirow{2}{*}{ Determinações } & \multicolumn{3}{|c|}{ Ano 94/95 } & \multicolumn{3}{|c|}{ Ano 95/96 } \\
\hline & OO & GM & GX & OO & GM & $\mathbf{G X}$ \\
\hline pH em água $(1: 2,5)$ & 5,0 & 4,5 & 4,7 & 5,1 & 5,0 & 4,9 \\
\hline $\mathrm{P}\left(\mathrm{mg} / \mathrm{dm}^{3}\right)$ & 23 & 18 & 9 & 15 & 13 & 7 \\
\hline $\mathrm{K}\left(\mathrm{mg} / \mathrm{dm}^{3}\right)$ & 34 & 45 & 45 & 36 & 36 & 33 \\
\hline $\mathrm{Ca}\left(\mathrm{mmol}_{\mathrm{c}} / \mathrm{dm}^{3}\right)$ & 15 & 22 & 14 & 17 & 22 & 19 \\
\hline $\mathrm{Mg}\left(\mathrm{mmol}_{\mathrm{c}} / \mathrm{dm}^{3}\right)$ & 11 & 8 & 2 & 7 & 6 & 2 \\
\hline $\mathrm{Al}\left(\mathrm{mmol}_{\mathrm{c}} / \mathrm{dm}^{3}\right)$ & 12 & 8 & 4 & 12 & 4 & 2 \\
\hline $\mathrm{H}+\mathrm{Al}\left(\mathrm{mmol}_{\mathrm{c}} / \mathrm{dm}^{3}\right)$ & 110 & 88 & 45 & 137 & 88 & 50 \\
\hline $\mathrm{SB}\left(\mathrm{mmol}_{\mathrm{c}} / \mathrm{dm}^{3}\right)$ & 27 & 31 & 17 & 25 & 29 & 22 \\
\hline $\mathrm{t}\left(\mathrm{mmol}_{\mathrm{c}} / \mathrm{dm}^{3}\right)$ & 39 & 39 & 21 & 37 & 33 & 24 \\
\hline $\mathrm{T}\left(\mathrm{mmol}_{\mathrm{c}} / \mathrm{dm}^{3}\right)$ & 137 & 119 & 62 & 162 & 117 & 72 \\
\hline $\mathrm{m}(\%)$ & 31 & 20 & 19 & 33 & 12 & 8 \\
\hline $\mathrm{V}(\%)$ & 20 & 26 & 28 & 15 & 25 & 30 \\
\hline Carbono $(\mathrm{g} / \mathrm{kg})$ & 84 & 39 & 17 & 65 & 35 & 16 \\
\hline Mat.Org. (g/kg) & 146 & 67 & 30 & 112 & 59 & 27 \\
\hline Areia $(\mathrm{g} / \mathrm{kg})$ & 260 & 100 & 320 & 320 & 80 & 350 \\
\hline Silte $(\mathrm{g} / \mathrm{kg})$ & 460 & 540 & 550 & 350 & 370 & 240 \\
\hline Argila (g/kg) & 280 & 360 & 130 & 330 & 550 & 410 \\
\hline
\end{tabular}

Ciênc. agrotec., Lavras. V.27, n.3, p.578-584, maio/jun., 2003 


\section{RESULTADOS E DISCUSSÃO}

Os resultados médios de produção de sementes de diferentes cultivares irrigadas de arroz, obtidos em três tipos de solos de várzea, em 94/95, estão apresentados na Tabela 2.

Pelos resultados, observa-se que, independentemente da cultivar estudada, houve uma maior produção de sementes no Gleissolo Háplico, seguido do Gleissolo Melânico e, no Organossolo Fólico, foram observados os menores valores de produção. Na comparação entre cultivares, nota-se que não houve diferenças de produção para as sementes produzidas no Gleissolo Háplico. Já no Gleissolo Melânico e no Organossolo Fólico, as cultivares Urucuia e MG 1 foram mais produtivas que as demais. Para o ano de 95/96, verifica-se pela Tabela 4 que a produção de sementes também foi maior no Gleissolo Háplico, embora os resultados não tenham diferido daqueles obtidos no Gleissolo Melânico. Semelhantemente ao ocorrido no ano anterior, as menores produções de sementes ocorreram no Organossolo Fólico. Entretanto, na comparação entre as cultivares, não houve diferença significativa para essa variável anali- sada. Nesse contexto, vários trabalhos envolvendo competição regional de cultivares e linhagens de arroz irrigado foram estudados por Soares \& Morais (1986) e Bacha et al. (1997), e esses autores observaram, de maneira geral, que essas diferenças em produtividade são atribuídas principalmente às diversificações de solo, clima e manejo, embora, de acordo com Soares et al. (1995), a rigor, pode-se considerar que as cultivares Capivari, Urucuia, Sapucaí e Inca têm potencial semelhante para produção de sementes.

Os resultados médios para qualidade fisiológica de sementes (germinação, $1^{\text {a }}$ contagem do teste de germinação e comprimento de raiz) das diversas cultivares irrigadas de arroz, produzidas nos anos 94/95 e 95/96 em três tipos de solos de várzea, estão apresentados nas Tabelas 3, 4 e 5 .

Pelos resultados da Tabela 3 (ano 94/95), observa-se que as sementes produzidas no Gleissolo Háplico apresentaram melhor qualidade fisiológica (germinação, $1^{\text {a }}$ contagem do teste de germinação e comprimento de raiz) do que aquelas produzidas nos demais tipos de solo, independente da cultivar estudada.

TABELA 2 - Resultados médios de produção de sementes de cinco cultivares irrigadas de arroz, em três solos de várzea, em Cambuquira (MG), no ano 94/95.

\begin{tabular}{|c|c|c|c|c|}
\hline \multirow[t]{2}{*}{ Cultivar } & \multicolumn{4}{|c|}{ Solo } \\
\hline & Organossolo Fólico & GleissoloMelânico & Gleissolo Háplico & Média \\
\hline Capivari & 3864,5 b $\quad$ B & $4609,2 \quad b \quad B$ & 6135,2 a A & $4869,7 \quad \mathrm{~B}$ \\
\hline Sapucaí & 3437,5 b $\quad$ B & $4656,0 \quad \mathrm{~b} \quad \mathrm{~B}$ & 6953,0 a $A$ & $5015,5 \quad \mathrm{~B}$ \\
\hline Urucuia & 6078,0 a $\mathrm{A}$ & 6791,5 a A & 7098,7 a A & $6656,1 \mathrm{~A}$ \\
\hline Inca & $3270,7 \quad$ b $\quad B$ & $3552,0 \quad$ b $\quad$ B & 6463,5 a A & $4428,8 \quad \mathrm{~B}$ \\
\hline MG 1 & 5411,5 b A & 6916,5 a A & 7150,7 a A & $6492,9 \mathrm{~A}$ \\
\hline Média & $4412,4 \mathrm{c}$ & $5305,1 \mathrm{~b}$ & $6760,3 \mathrm{a}$ & \\
\hline
\end{tabular}

Médias seguidas pela mesma letra minúscula na linha e maiúscula na coluna não diferem entre si a $5 \%$ de probabilidade pelo teste de Tukey.

TABELA 3 - Resultados médios de germinação, $1^{\text {a }}$ contagem do teste de germinação e comprimento de raiz de sementes de arroz colhidas em três tipos de solo de várzea em Cambuquira (MG), no ano 94/95.

\begin{tabular}{|c|c|c|c|}
\hline \multirow{2}{*}{ Solo } & \multicolumn{3}{|c|}{ Avaliações } \\
\hline & Germinação (\%) & $1^{\mathrm{a}}$ Contagem (\%) & Comp. Raiz (cm) \\
\hline Organossolo Fólico & $86 \quad \mathrm{~B}$ & $85 \quad \mathrm{~B}$ & $6,5 \quad \mathrm{~B}$ \\
\hline Gleissolo Melânico & $88 \quad \mathrm{~B}$ & $87 \quad \mathrm{~B}$ & $7,3 \quad \mathrm{~B}$ \\
\hline Gleissolo Háplico & $92 \mathrm{~A}$ & $90 \mathrm{~A}$ & $8,8 \mathrm{~A}$ \\
\hline
\end{tabular}

Médias seguidas pela mesma letra na coluna não diferem entre si a $5 \%$ de probabilidade pelo teste de Tukey. 
Comportamento semelhante pode ser observado no ano 95/96 (Tabela 4), embora a qualidade fisiológica (germinação e $1^{\mathrm{a}}$ contagem do teste de germinação) das sementes produzidas no Gleissolo Háplico e Gleissolo Melânico não tenham apresentado diferenças significativas.

Pela comparação da qualidade fisiológica das sementes (germinação e $1^{\text {a }}$ contagem do teste de germinação), entre cultivares, verifica-se na Tabela 5 (ano 95/96) que a 'Urucuia' e a 'MG 1' apresentaram qualidade inferior às demais, as quais não diferiram entre si. Entretanto, de uma maneira geral, nota-se que, em qualquer tipo de solo estudado, as sementes das diferentes cultivares apresentaram alto potencial germi- nativo, uma vez que todas estavam com germinação acima do padrão mínimo para a classe básica (80\%) exigida pela Comissão Estadual de Sementes e Mudas de Minas Gerais (CESM/MG) (Minas Gerais, 1985).

De acordo com os resultados da presente pesquisa, no geral, as produções e a qualidade fisiológica das sementes variaram tanto para cultivares quanto para a classe de solo estudada. Isso evidencia a importância de se fazer estudos relacionados ao comportamento de cultivares em diferentes solos, visando a garantir uma melhor produtividade. Contudo, experimentos de campo são susceptíveis às variações de clima, ficando bem embasados quando repetidos por vários anos.

TABELA 4 - Resultados médios de produção, germinação e $1^{\text {a }}$ contagem do teste de germinação obtidos de sementes de arroz colhidas em três tipos de solo de várzea em Cambuquira (MG), no ano 95/96.

\begin{tabular}{|c|c|c|c|}
\hline \multirow{2}{*}{ Solo } & \multicolumn{3}{|c|}{ Avaliações } \\
\hline & Produção (kg/ha) & Germinação (\%) & $1^{\mathrm{a}}$ Contagem (\%) \\
\hline Organossolo Fólico & $5780,2 \quad$ B & 87 B & $82 \mathrm{~B}$ \\
\hline Gleissolo Melânico & $7904,5 \mathrm{~A}$ & $91 \mathrm{~A}$ & $87 \mathrm{AB}$ \\
\hline Gleissolo Háplico & $8240,0 \mathrm{~A}$ & $92 \mathrm{~A}$ & $89 \mathrm{~A}$ \\
\hline
\end{tabular}

Médias seguidas pela mesma letra na coluna não diferem entre si a $5 \%$ de probabilidade pelo teste de Tukey.

TABELA 5 - Resultados médios de germinação e $1^{\text {a }}$ contagem do teste de germinação obtidos de sementes de cinco cultivares irrigadas de arroz colhidas em três solos de várzea em Cambuquira (MG), no ano $95 / 96$.

\begin{tabular}{|c|c|c|}
\hline \multirow{2}{*}{ Cultivares } & \multicolumn{2}{|c|}{ Avaliações } \\
\hline & Germinação (\%) & $1^{\text {a }}$ Contagem (\%) \\
\hline Capivari & $93 \mathrm{~A}$ & $91 \mathrm{~A}$ \\
\hline Sapucaí & $93 \mathrm{~A}$ & $91 \mathrm{~A}$ \\
\hline Urucuia & $85 \quad \mathrm{~B}$ & $79 \quad \mathrm{~B}$ \\
\hline Inca & $94 \mathrm{~A}$ & $90 \mathrm{~A}$ \\
\hline MG 1 & $84 \quad \mathrm{~B}$ & $77 \quad \mathrm{~B}$ \\
\hline
\end{tabular}

Médias seguidas pela mesma letra na coluna não diferem entre si a $5 \%$ de probabilidade pelo teste de Tukey.

Ciênc. agrotec., Lavras. V.27, n.3, p.578-584, maio/jun., 2003 


\section{CONCLUSÕES}

Para as condições em que foi desenvolvido este trabalho, pode-se concluir que:

a) O Gleissolo Háplico proporcionou maiores produções de sementes de arroz irrigado e, no Organossolo Fólico, houve as menores produtividades;

b) As sementes produzidas no Gleissolo Háplico apresentaram melhor qualidade fisiológica;

c) No ano 94/95, as cultivares Urucuia e MG 1 foram as mais produtivas.

\section{REFERÊNCIAS BIBLIOGRÁFICAS}

BACHA, R. E.; ISHIY, T.; KNOBLAUCH, R.; ALFONSO-MOREL, D. Competição regional de cultivares e linhagens de arroz irrigado em Santa Catarina, 1996/97. In: REUNIÃO DA CULTURA DO ARROZ IRRIGADO, 22., 1997, Balneário Camboriú. Anais... Itajaí: EPAGRI, 1997. p. 33-36.

BRASIL. Ministério da Agricultura e Reforma Agrária. Regras para análise de sementes. Brasília: SNAD/DNDV/CLAV, 1992. 365 p.

CAMARGO, O. A.; MONIZ, A. C.; JORGE, J. A.; VALADARES, J. M. A. S. Métodos de análise química, mineralógica e física de solos do Instituto Agronômico de Campinas. Campinas: IAC, 1986. 94 p.

COMISSÃO DE FERTILIDADE DO SOLO DO ESTADO DE MINAS GERAIS. Recomendação para o uso de corretivos e fertilizantes em Minas Gerais: $4^{\mathrm{a}}$ aproximação. Lavras, 1989. 176 p.

CURI, N.; RESENDE, M.; SANTANA, D. P. Solos de várzea de Minas Gerais: exploração racional de várzeas II. Informe Agropecuário, Belo Horizonte, v. 13, n. 152, p. 3-13, 1988.

EMPRESA BRASILEIRA DE PESQUISA AGROPECUÁRIA. Súmula. Rio de Janeiro, 1979. 83 p. (EMBRAPA-SNLCS. Série Miscelânia, 1).

EMPRESA BRASILEIRA DE PESQUISA AGROPECUÁrIA. Centro Nacional de Pesquisa de Solos. Sistema brasileiro de classificação de solos. Brasília; Rio de Janeiro, 1999. 412 p.
FARIA, L. A. L.; AZEVEDO, J. T. de. Produção de sementes de arroz. Informe Agropecuário, Belo Horizonte, v. 10, n. 14, p. 13-19, 1984.

FORNASIERE FILHO, D.; FORNASIERE, J. L. Manual da cultura do arroz. Jaboticabal: FUNEP, 1993. $221 \mathrm{p}$.

GUILHERME, L. R. G. Calagem e inundação em solos de várzea cultivados com arroz: alterações em pH, nitrogênio, fósforo e enxofre. 1990. $113 \mathrm{f}$. Dissertação (Mestrado em Solos e Nutrição de Plantas) - Escola Superior de Agricultura de Lavras, Lavras.

LOPES, A. S. Guia das melhores técnicas agrícolas. São Paulo: ANDA, 1996. 28 p.

MALAVOLTA, E.; FORNASIERE FILHO, D. Nutrição mineral da cultura do arroz. In: FERREIRA, M. E.; YAMADA T.; MALAVOLTA, E. Cultura do arroz de sequeiro: fatores afetando a produtividade. Piracicaba: Instituto da Potassa e Fosfato, 1983. p. 95-140.

MINAS GERAIS. Secretaria de Estado da Agricultura. Normas, padrões e procedimentos para a produção de sementes básicas, certificadas e fiscalizadas. 2. ed. Belo Horizonte, 1985. $110 \mathrm{p}$.

NOVAES, G. de. Conhecer para explorar: várzeas: produção segura de alimentos: exploração racional de várzeas I. Informe Agropecuário, Belo Horizonte, v. 13, n. 151, p. 1, 1988.

RESENDE, M. Pedologia. Viçosa: Universidade Federal de Viçosa, 1982. $110 \mathrm{p}$.

RURALMINAS. Coordenadoria de irrigação e drenagem. Programa de aproveitamento de várzeas do estado de Minas Gerais: PROVÁRZEAS - MG. Informe Agropecuário, Belo Horizonte, v. 6, n. 65, p. 8-13, maio 1980.

SOARES, A. A.; REIS, M. de S.; CORNÉLIO, V. M. de O.; SOARES, P. C. Urucuia, Sapucaí e Capivari: novos cultivares de arroz irrigado para o estado de Minas Gerais. Revista Ceres, Lavras, v. 42, n. 240, p. 225-232, mar./abr. 1995. 
SOARES, P.C.; MORAIS, O.P. de. Competição regional de cultivares de arroz irrigado. In: REUNIÃO NACIONAL DE PESQUISA DE ARROZ, 2., 1980, Goiânia. Resumos... Brasília: EMBRAPA-DDT, 1986. p. 163-166.

VETTORI, L. Métodos de análise de solo. Rio de Janeiro: Ministério da Agricultura-Equipe de Pedologia e Fertilidade do Solo, 1969. 24 p. (Boletim Técnico, 7).
VIEIRA, A. R.; VIEIRA, M. G. G. C.; CARVALHO, V. D. de; FRAGA, A. C. Efeitos de tratamentos pré-germinativos na superação da dormência de sementes de arroz e na atividade enzimática da peroxidase. Pesquisa Agropecuária Brasileira, Brasília, v. 29, n. 4, p. 535-542, abr. 1994. 